UCRL-JC-126562

PREPRINT

\title{
Chemical Reaction and Equilibration Mechanisms in Detonation Waves
}

\author{
Craig M. Tarver
}

This paper is prepared for submittal to the

1997 Topical Conference on Shock Compression of Condensed Matter

July 27-Aug. 1, 1997, Univ. of Massachusetts, Amherst, MA.

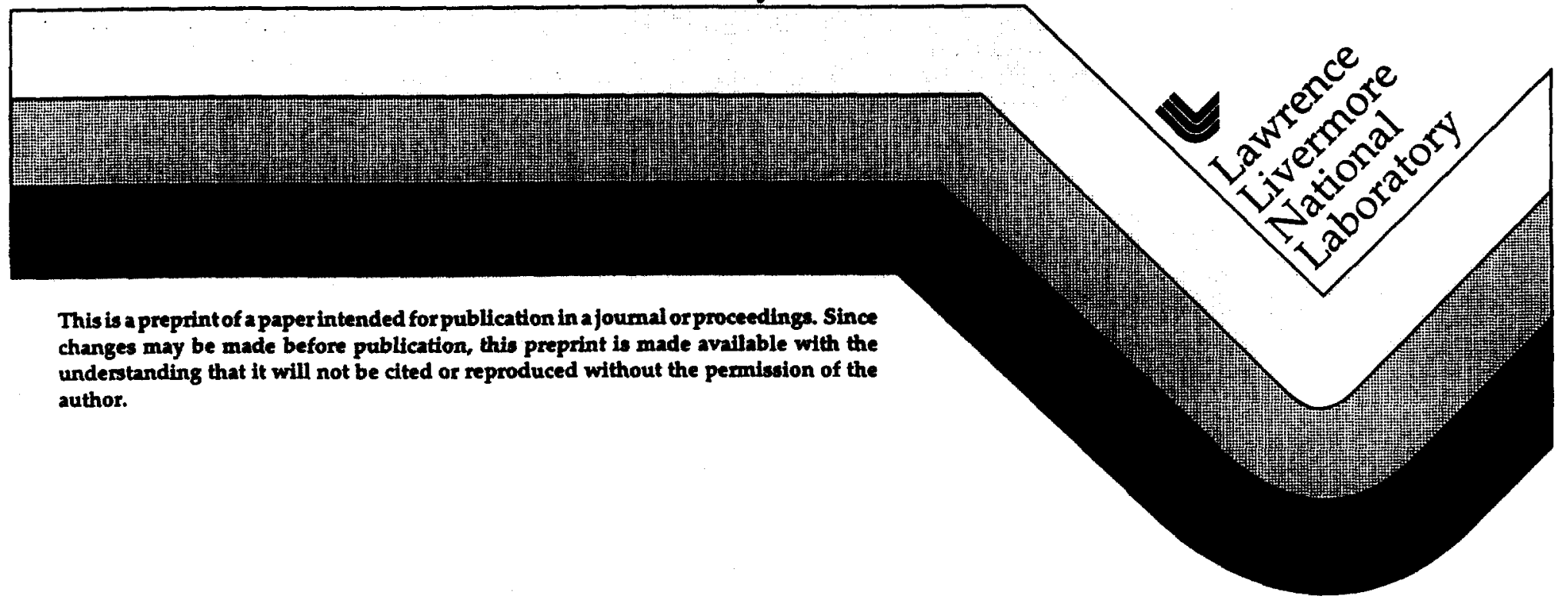




\section{DISCLAIMER}

This document was prepared as an account of work sponsored by an agency of the United States Government. Neither the United States Government nor the University of California nor any of their employees, makes any warranty, express or implied, or assumes any legal liability or responsibility for the accuracy, completeness, or usefulness of any information, apparatus, product, or process disclosed, or represents that its use would not infringe privately owned rights. Reference herein to any specific commercial product, process, or service by trade name, trademark, manufacturer, or otherwise, does not necessarily constitute or imply its endorsement, recommendation, or favoring by the United States Government or the University of Califomia. The views and opinions of authors expressed herein do not necessarily state or reflect those of the United States Government or the University of California, and shall not be used for advertising or product endorsement purposes. 


\title{
CHEMICAL REACTION AND EQUILIBRATION MECHANISMS IN DETONATION WAVES
}

\author{
Craig M. Tarver \\ Lawrence Livermore National Laboratory, \\ P.O. Box 808, L-282, Livermore, CA 94551
}

Experimental and theoretical evidence for the nonequilibrium Zeldovich-von Neumann-Doring (NEZND) theory of self-sustaining detonation is presented. High density, high temperature transition state theory is used to calculate unimolecular reaction rate constants for the initial decomposition of gaseous norbornene, liquid nitromethane, and solid, single crystal pentaerythritol tetranitrate as functions of shock temperature. The calculated rate constants are compared to those derived from experimental induction time measurements at various shock and detonation states. Uncertainties in the calculated shock and von Neumann spike temperatures are the main drawbacks to calculating these reaction rates. Nanosecond measurements of the shock temperatures of unreacted explosives are necessary to reduce these uncertainties.

\section{INTRODUCTION}

The nonequilibrium Zeldovich-von NeumannDoring (NEZND) theory of detonation (1-5) was developed as a framework in which to study the major chemical and physical processes that precede and follow exothermic chemical reaction. These nonequilibrium processes determine the time required for the onset of chemical reaction, control the energy release rates, and supply the mechanism by which the chemical energy sustains the leading shock wave front structure. The three-dimensional shock front structure, the nonequilibrium excitation and relaxation processes, and the chemical reaction rates in gaseous detonation waves are fairly well understood $(1,2)$. The high pressures $(20-40 \mathrm{GPa})$, densities $\left(2.5 \mathrm{~g} / \mathrm{cm}^{3}\right)$, and temperatures $(3000-5000$ $\mathrm{K})$ generated in less than a microsecond in condensed phase detonation waves traveling at velocities approaching $10 \mathrm{~mm} / \mu \mathrm{s}$ create environments that are extremely difficult to study. Calculations of initial unimolecular decomposition rates under shock and detonation conditions are presented in this paper.

\section{THE NEZND THEORY OF DETONATION}

Figure 1 shows the four major regions and several

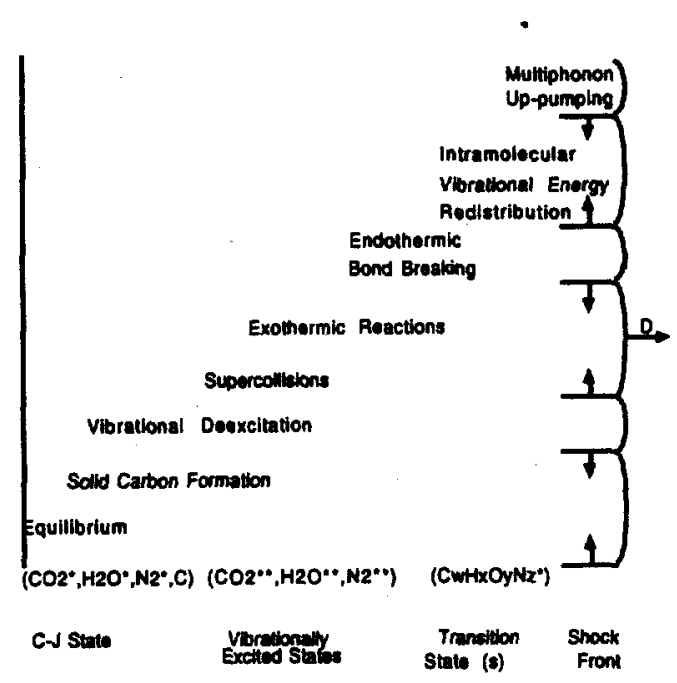

FTGURE 1. Nonequilibrium ZND (NEZND) model of detonation in an organic solid or liquid explosive

chemical processes that occur within the reaction zone of an organic solid or liquid explosive, $\mathrm{C}_{w} \mathrm{H}_{\mathrm{x}} \mathrm{OyN} \mathrm{N}_{\mathrm{z}}$. The first region is the leading shock wave front, which consists of a three-dimensional arrangement of Mach stem interactions. The detonation wave front structure in condensed phase 
explosives was discussed by Tarver et al. (4).

Following shock front compression, the second region in Fig. 1 is dominated by the flow of the excess phonon energy into the low frequency vibrational modes of the molecule by "multiphonon up-pumping" (6) and the subsequent energy flow from the low frequency "doorway" modes to the high frequency modes by intramolecular vibrational energy redistribution (IVR) (7). Hong et al. (8) measured the up-pumping and IVR rates in liquid nitromethane (NM) and found that complete equilibration required approximately 100 ps. Molecular dynamics studies of these relaxation rates have shown that the equilibration times depend on the number of doorway modes and the shock pressure. Large molecules with several doorway modes, such as octahydro-1,3,5,7-tetranitro-1,3,5,7-tetrazocine (HMX), triaminotrinitrobenzene (TATB), and pentaerythritol tetranitrate (PETN), equilibrate in approximately $10 \mathrm{ps}$ (9). The establishment of vibrational equilibrium is a necessary condition for chemical decomposition, because the initial bond breaking reaction proceeds through a transition state created by high vibrational excitation of one of the highest frequency modes.

The third region of Fig. 1 begins at the transition state (or states), which is followed by the chemical reconstitution process in several small stable reaction product molecules are produced. This region is called the "von Neumann spike" or the "chemical peak" in the condensed phase explosives literature. Hydrodynamic pressure and particle velocity measurements with nanosecond time resolution have yielded considerable information about the average properties of this state (10). Once the exothermic chain reaction process is initiated, highly vibrationally excited products form and interact with the unreacted molecules and each other to greatly increase the rates of decomposition. Large quantities of vibrational energy have been shown to be rapidly transferred by "supercollisions" involving highly vibrationally excited molecules (5).

The fourth region in Fig. 1 is dominated by the expansion and vibrational deexcitation of the stable reaction products plus the diffusion controlled formation of solid products, such as carbon particles in underoxidized explosives. Nanosecond experimental techniques have measured the average pressures, particle velocities, and temperatures as the Chapman-Jouguet (C-J) state of thermal and chemical equilibrium is approached (11). In addition to vibrational-rotational and vibrational-translational energy transfer, an essential physical process in the attainment of thermal equilibrium and the continued propagation of a self-sustaining detonation wave is the amplification of pressure wavelets by the chemical energy released during transitions from higher to lower vibrational levels during compression by these wavelets of specific frequencies. These process was recently shown to be the mechanism by which the internal chemical energy of the product molecules sustains the leading shock wave front at an overall constant velocity (5).

\section{REACTION RATE CONSTANTS}

Calculating the reaction rate constants for the transition states in shocked and detonating materials is the main subject of this paper. Reaction rate constants calculated for the shock-induced decomposition of gaseous norbornene, liquid NM, and solid PETN using high density, high temperature transition state theory are compared to the available experimental induction time data for various shock temperatures. Experimental data for unimolecular gas phase reactions under shock conditions has shown that the reaction rates obey the Arrhenius law:

$$
\mathrm{K}=\mathrm{A} \mathrm{e}^{-\mathrm{E} / \mathrm{RT}}
$$

where $A$ is a frequency factor, $E$ is the activation energy, and $T$ is temperature, at low temperatures, but "fall-off" to less rapid rates of increase at high temperatures (12). Nanosecond reaction zone profile measurements for solid explosives overdriven or "supracompressed" to pressures and temperatures exceeding those attained in self-sustaining detonation waves have shown that the reaction rates increase very slowly with shock temperature (13). Eyring (14) attributed this "falloff" in unimolecular rates at the extreme temperature and density states attained in shock and detonation waves to the close proximity of vibrational states, which causes the high frequency mode that becomes the transition state to rapidly equilibrate with the surrounding modes by IVR. Thus these interacting modes form a "pool" of vibrational energy in which the energy required for decomposition is shared. Any large quantity of vibrational energy that a specific mode receives from an excitation process is equilibrated among the modes before decomposition can occur. Conversely, sufficient vibrational energy from the entire pool of oscillators is statistically present in the transition state long enough to cause reaction. When the total 
energy in the interacting vibrational modes equals the activation energy, the reaction rate constant $K$ is:

$$
K=(k T / h) e^{-s} \sum_{i=0}^{s-1}(E / R T)^{i} e^{-E / R T / i !}
$$

where $k, h$, and $R$ are Boltzmann's, Planck's, and the gas constant, respectively, and $s$ is the number of the vibrational modes interacting with the dissociation mode. The main effect of this rapid IVR among $s+1$ modes at the high densities and temperatures reached in detonation waves is to decrease the rate constant dependence on temperature. Tarver (3) demonstrated that reasonable reaction rate constants could be calculated for detonating solid and liquid explosives using Eq. (2) with realistic equations of state and values of $\mathrm{s}$. For the high densities but lower temperatures attained in shock initiation of homogeneous liquid and solid explosives, the reaction rate constants from Eq. (2) are greater than those predicted by Eq. (1). To determine whether Eq. (2) is valid under shock conditions, rate constants from Eqs. (1) and (2) are compared to shock initiation induction time results for NM and PETN.

\section{COMPARISON OF RESULTS}

The most complete set of gas phase unimolecular rate measurements is for norbornene decomposing to 1,3-cyclopentadiene and ethylene (15). Figure 2 shows that the reaction rates calculated using Eq. (2) with $s=20$ and $E=45.39 \mathrm{kcal} / \mathrm{m}$ agree extremely well with the measured rates, which are slower than the Arrhenius rate in Fig. 2 that fits several sets of experimental data below $1000 \mathrm{~K}$ (16). Eyring (14) and Tarver (3) found that twenty is a reasonable number of neighboring modes for many reactions, because only the modes involving 6 or 7 atoms are close enough to rapidly IVR with the reacting mode.

The second comparison is for the shock initiation data for liquid NM, summarized by Sheffield et al. (17) and Yoo and Holmes (18). The induction times for the onset of chemical reaction for transparent liquid explosives are measured at various input shock pressures. The induction time $\tau_{i}$ in thermal ignition theory (19) is related to the reaction rate constant $\mathrm{K}$ by:

$$
\tau_{i}^{-1}=\mathrm{QEK} / \mathrm{C}_{\mathrm{v}} \mathrm{RT}^{2}
$$

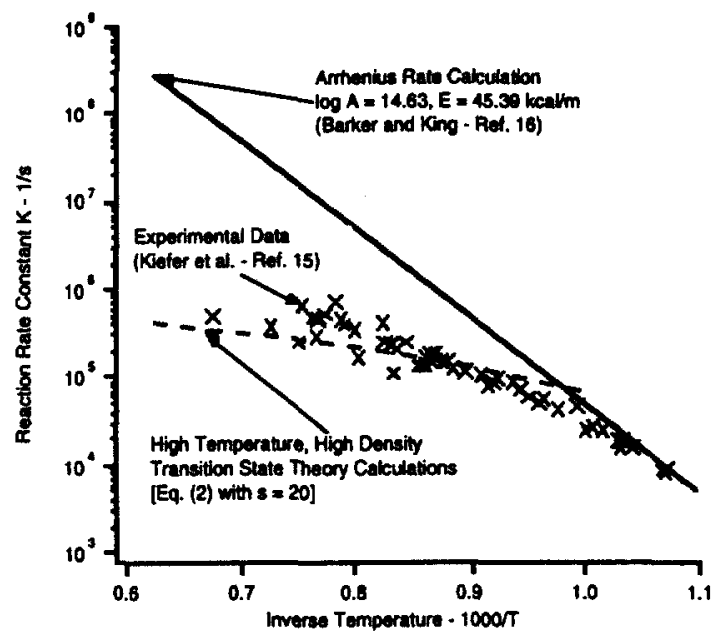

FIGURE 2. Reaction rate constant versus inverse temperature for the unimolecular decomposition of norbomene

where $Q$ is the heat of reaction and $C_{y}$ is the heat capacity. Thus, to relate the input shock pressure to temperature, an equation of state is required. Two excellent equations of state for NM have been published. Both included the increase in $C_{v}$ as $T$ increases, but they made different assumptions concerning the dependence of $(\mathrm{dp} / \mathrm{dT})_{\mathrm{v}}$ on pressure. Cowperthwaite and Shaw (20) assumed that (dp/dT), is a constant, while Lysne and Hardesty (21) assumed that it increases as the density increases. Figure 3 shows the reaction rate constant versus inverse temperature results for NM calculated from the experimental induction times using Eq. (3) with shock temperatures calculated by these two EOS's. Also shown in Fig. 3 are the rates calculated using Eq. (1) with the gas phase values of $A=4.0 \times 10^{15} \mathrm{~s}^{-1}$ and $\mathrm{E}=59 \mathrm{kcal} / \mathrm{m}(19)$ and using Eq. (2) with $\mathrm{s}=$ 14 , since NM has 15 vibrational modes. Despite the uncertainties in shock temperatures, Eq. (2) with $s=$ 14 agrees well with the experimental data. The von Neumann spike rates of approximately $10^{8} \mathrm{~s}^{-1}$ shown in Fig. 3 agree with the nanosecond reaction times for detonating NM measured by Sheffield (22).

Figure 4 shows the induction time data for single crystal PETN reported by Dick et al. (23). The Jones-Wilkins-Lee (JWL) equation of state for unreacted PETN developed by Tarver et al. (24) was used to calculate the shock temperatures with a constant $\mathrm{C}_{v}$ intermediate between the ambient temperature value and the maximum value. Also shown in Fig. 4 are the straight line for Eq. (1) with 


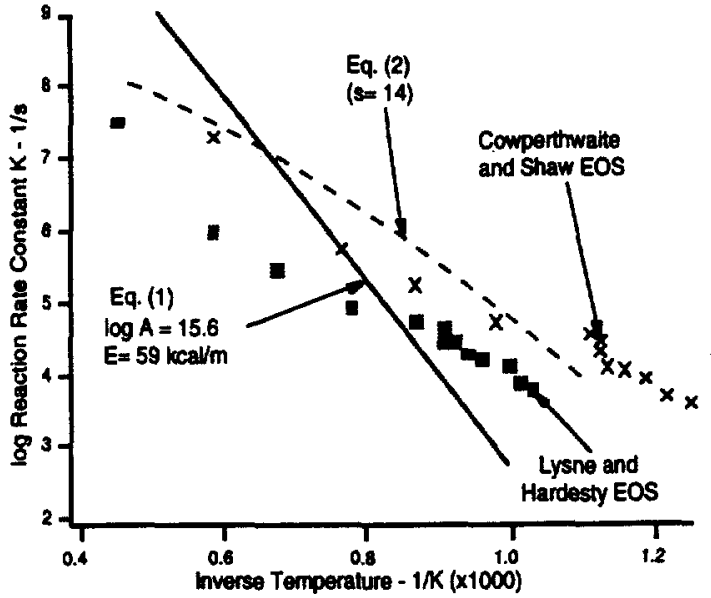

FGURE 3. Reaction rate constants for nitromethane as functions of shock temperature

$E=47 \mathrm{kcal} / \mathrm{m}$ and $\mathrm{A}=\mathrm{kT} / \mathrm{h}$ and the curves for $\mathrm{s}=$ 15 and $s=20$ in Eq. (2). As for NM, the high density, high temperature transition state rate constants agree well with the PETN data, even when extrapolated to the von Neumann spike state of 2300 - $2500 \mathrm{~K}(25)$. The $\mathrm{s}=15$ calculation appears to be closer to the experimental data than $s=20$, but accurate shock temperature measurements are needed before conclusions can be drawn about the number of vibrations interacting in the PETN transition state.

\section{SUMMARY}

High density, high temperature transition state calculations yield good agreement with measured reaction rates in shocked gases, liquids, and solids.

\section{ACKNOWLEDGMENTS}

This work was performed under the auspices of the U.S. Department of Energy by Lawrence Livermore National Laboratory (contract no. W-7405-ENG-48).

\section{REFERENCES}

1. Tarver, C. M., Combustion and Flame 46, 111-134 (1982).

2. Tarver, C. M., Combustion and Flame 46, 135-156 (1982).

3. Tarver, C. M., Combustion and Flame 46, 157-176 (1982).

4. Tarver, C. M., Fried, L. E., Ruggerio, A. J., and Calef, D. F., Tenth international Detonation Symposium, ONR 33395-12, Boston, MA, 1993, pp. 3-10.

5. Tarver, C. M., to appear in J. Phys. Chem. July 10, 1997.

6. Tokmakoff, A. Fayer, M. D. and Dlott, D. D., J. Phys.

Chem.. 97, 1901-1911 (1993)

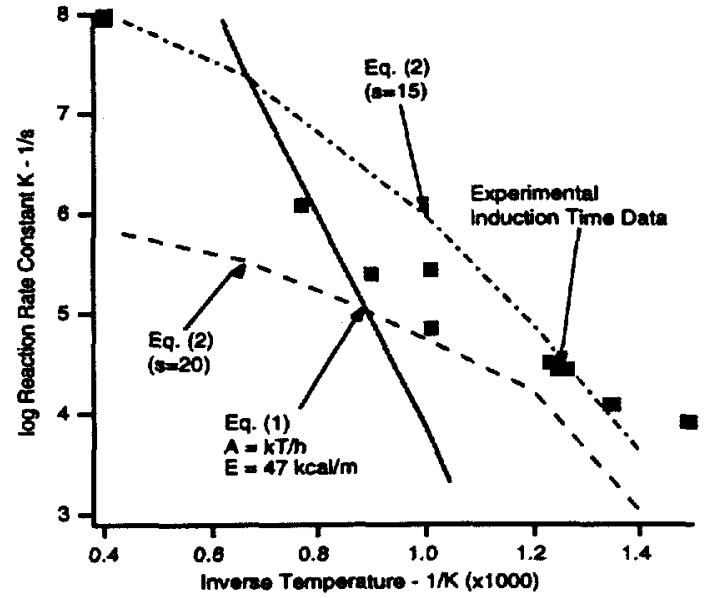

FIGURE 4. Reaction rate constants for single crystal PETN as functions of shock temperature

7. Weston, Jr., R. E. and Flynn, G. W., Ann. Rev. Phys. Chem. 43, 559-599 (1993).

8. Hong, X., Chen, S., and Dlott, D. D., J. Phys. Chem. 99; $9102-$ 9108 (1995).

9. Fried, L. E. and Tarver, C. M., Shock Compression of Condensed Matter-1995, Schmidt, S. C. and Tao, W. C., eds., AlP, New York, 1996, pp. 179-182.

10. Tarver, C. M., Tao, W. C., and Lee, C. G., Propellants, Explosives, Pyrotechnics 21, 238-246 (1996).

11. Hayes, B. and Tarver, C. M., Seventh Symposium (International) on Detonation, NSWC MP86-194, Annapolis, MD, 1981, pp. 1029-1037.

12. Kiefer, J. H. and Shah, J. N. J. Phys. Chem. 91, 3024-3033 (1987).

13. Green, L. G., Tarver, C. M., and Erskine, D. J., Ninth Symposium (International) on Detonation, OCNR113291-7, Portland, OR, 1989, pp. 670-678.

14. Eyring, H., Science 199, 740-743 (1978).

15. Kiefer, J. H., Kumaran, S. S., and Sundaram, S. J., J. Chem. Phys. 99, 3531 (1993).

16. Barker, J. R. and King, K. D., J. Chem. Phys. 103, 4953 (1995).

17. Sheffield, S. A., Engelke, R., and Alcon, R. R., Ninth Symposium (International) on Detonation, OCNR113291-7, Portland, OR, 1989, pp. 39-49.

18. Yoo, C. S. and Hoimes, N. C., High-Pressure Science and Technology-1993, Schmidt, S. C., Shaner, J. W., Samara, G. A., and Ross, M., eds., AIP, New York, 1994, pp. 1567-1570

19. Hardesty, D. R., Combustion and Flame 27, 229-251 (1976).

20. Cowperthwaite, M. and Shaw, R. J. Chem. Phys. 53, 555-560 (1970).

21. Lysne, P. C. and Hardesty, D. R. J. Chem. Phys. 59, 65126523 (1973)

22. Sheffield, S. A., LANL, private communication, 1997.

23. Dick, J. J., Mulford, R. N., Spencer, W. J., Pettit, D. R., Garcia, E., and Shaw, D. C., J. Appl. Phys. 70, 3572-3587 (1991).

24. Tarver, C. M., Breithaupt, R. D., and Kury, J. W., J. Appl. Phys. 81, 7193-7202 (1997).

25. Yoo, C. S., Holmes, N. C., and Souers, P. C., Shock Compression of Condensed Matter-1995, Schmidt, S. C. and Tao, W. C., eds., AIP, New York, 1996, pp. 913-916. 


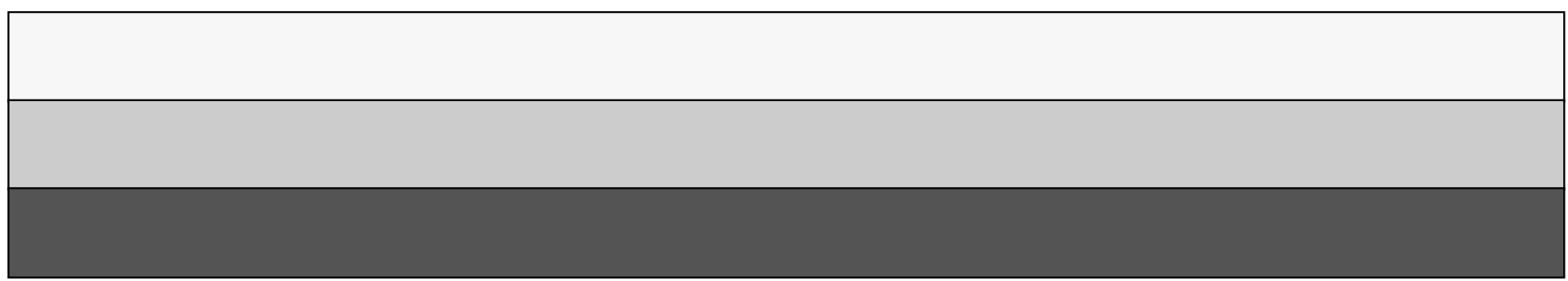

